\title{
Nuestro derecho y la postpandemia
}

Our right and the post-pandemic

\author{
E. Raúl Zaffaroni ${ }^{1}$ \\ Universidad de Buenos Aires - Argentina
}

Revista Derechos en Acción ISSN 2525-1678/ e-ISSN 2525-1686

Año 5/N№ 15, Otoño 2020 (21 marzo a 21 junio), 401-414

DOI: https://doi.org/10.24215/25251678e406

\section{Pandemia y colonialismo}

Cuando se producen cambios de poder planetario, da la sensación de que la historia se acelera. Los cambios actuales eran previsibles. Entre otros, Francisco lo dijo en la Laudato si: esto no se sostiene. La pandemia precipita las cosas, pero además de las advertencias de la OMS, tampoco es algo nuevo en la historia.

Si quitamos la máscara ideológica del neoliberalismo, veremos que el mundo está sufriendo un totalitarismo, en este caso financiero, que practica una nueva forma de colonialismo que podemos llamar tardocolonialismo, para diferenciarlo de las etapas anteriores, es decir, del originario y del neocolonialismo. Esta nueva etapa colonial ahora se enrosca sobre sí y paraliza la economía mundial.

El colonialismo tiene su historia, que no debe confundirse con la historia universal, como pretendía Hegel. Esa historia nos dice que no es la primera vez que una hegemonía mundial se enrosca, ni tampoco son ajenas a esto las infecciones.

\footnotetext{
Abogado, doctor en Derecho, profesor de derecho penal, ex Ministro de la Corte Suprema de Justicia de la Nación, actual Juez de la Corte Interamericana de Derechos Humanos.
} 
La revolución mercantil -que posibilitó el colonialismo-, fue impulsada por el comercio europeo con oriente, que llevó las ratas y la peste bubónica, matando a un tercio de la población europea.

Lanzados al colonialismo originario, los españoles contaminaron a los indios con enfermedades, producto de la domesticación europea de animales, contra las que los indios no tenían anticuerpos, lo que mató a la mitad de la población originaria. Al mismo tiempo, jerarquizó tanto su sociedad que, cuando con la revolución industrial apareció la burguesía europea, fue incapaz de crearla en España y se derrumbó su imperio.

Para satisfacer el extractivismo insaciable, se cometió el crimen del esclavismo contra los africanos, que trajeron la fiebre amarilla y, cuando el neocolonialismo quiso facilitar la comunicación interoceánica con el canal de Panamá, esa infección hizo fracasar la primera tentativa de construirlo.

El neocolonialismo cometió horripilantes genocidios, especialmente en África, hasta desembocar en una guerra interimperialista que, al final, desencadenó la llamada gripe española. En la segunda etapa de esa tragedia se enroscó, pues el genocidio fue cometido en su propio territorio, victimizando a personas tan pobres en melanina como sus líderes.

Ahora el tardocolonialismo financiero de las transnacionales, con su brutal depredación del medio ambiente y la destrucción indiscriminada de equilibrios biológicos, fue generando virus en serie, hasta producir uno que paralizó la economía mundial.

El actual recorte arbitrario de lo que nos explica la ciencia biológica, pretende que el enemigo sea el virus y, por ende, estaríamos en guerra contra el virus cuando, de existir alguna guerra, debería serlo contra la fábrica de virus en serie, que es, justamente, el actual totalitarismo financiero depredador del medio ambiente, que ha producido la vaca loca (por alimentar rumiantes con harina de cadáveres), la gripe asiática, la de Hong Kong, el VIH, la gripe porcina, el SARS, el Ébola, el coronavirus modelo 2015 y ahora la nueva versión 19. 
Como si eso fuese poco, fabrica luego las vacunas, las patentan y las venden a quienes pueden pagarlas: cada año mueren en la India 100.000 niños de neumonía, mientras la transnacional dueña de la patente de la vacuna embolsa miles de millones de dólares.

Esclavitud, sometimiento a servidumbre, crímenes masivos atroces, genocidios, glotonería hegemónica, concentración ilimitada de riqueza, suicidios de las sucesivas oligarquías enceguecidas por su afán insaciable de poder y generación de epidemias, son fenómenos entrelazados y presentes desde la gestación del colonialismo en Europa hasta todas sus sucesivas etapas en el mundo.

\section{La naturaleza del totalitarismo financiero}

Es claro que estamos sometidos a un poder planetario que concentra ilimitadamente riqueza, con la consiguiente exclusión genocida de miles de millones de personas, para lo cual ejerce sobre nuestra región un despiadado colonialismo succionador, mediante endeudamientos concertados por sus virreyes locales, que nos somete a jurisdicciones extranjeras.

Lo cierto es que este totalitarismo financiero equivale hoy a los de entreguerras, es decir que, para legitimar genocidios, ya no se usan camisas pardas ni negras ni se prometen paraísos de razas superiores puras o de sociedades sin clases en que todos seremos felices, sino que se vaticina una felicidad generosamente derramada desde la riqueza crecientemente concentrada.

El discurso con que se enmascara este totalitarismo no está escrito en Mein Kampf, sino en las obras de Milton Friedman y Friedrich von Hayek. Tampoco se promete el ario puro y el hombre nuevo, sino el homo economicus.

Este discurso es el que ahora confronta con los Derechos Humanos, incorporados al derecho internacional desde el final de la Segunda Guerra Mundial. Mientras estos últimos 
proclaman que todo ser humano es persona y, por el hecho de existir tiene unos derechos elementales y básicos, la ideología que se autodenomina neoliberal afirma que, por el mero hecho de haber nacido, un sujeto no tiene derecho a reclamar nada (así, von Hayeck). Si bien no todos los acólitos de esta idolatría son tan explícitos y sinceros, los cadáveres en el Mediterráneo o el experimento pinochetista de Friedman, demuestran que comparten esa premisa.

Los gerentes de este totalitarismo financiero no pueden hacer otra cosa que obtener ganancias sin respetar límite alguno, puesto que, con la financiarización de la economía, las corporaciones transnacionales son manejadas por tecnócratas que deben cumplir con ese objetivo o son reemplazados.

En ejecución de estos mandatos ineludibles, la conducta de los gerentes del totalitarismo financiero pasó a ser delincuencial a gran escala: extorsiones, trabajo esclavo, macroestafas, evasión fiscal, administraciones fraudulentas, destrucciones de ecosistemas, extinción de especies, desertificación, contaminación de aguas y atmósfera, encubrimiento de tráficos ilícitos, reciclajes de dinero, empresas fantasmas y, llegado el caso, también golpes de Estado y fusilamiento de población civil, todo se lo permiten sin límite alguno. La criminalidad organizada (organized crime) más poderosa del planeta es la que ejercen estos gerentes con sus macrodelitos. No debe extrañar, porque todos los totalitarismos fueron criminales; sólo cambian sus métodos, conforme a sus contextos de poder.

\section{La situación tardocolonial}

En nuestra realidad colonial de extrema concentración de riqueza, con los más altos coeficientes de Gini del planeta, la paralización hará caer en la pobreza a fajas de las clases medias. A las fuertes protestas de la prepandemia se sumarán las fajas medias desclasadas. Nuestros Estados no estuvieron preparados para responder con racionalidad a las demandas anteriores y, menos aún, lo estarán para las que vengan. 
Si aspiramos a que la conflictividad que anuncia esta emergencia halle soluciones no violentas y, por ende, a que nuestros Estados puedan ofrecer soluciones racionales en el marco democrático y republicano, el primer paso debe ser reconocer la dura realidad de la que deberemos partir, es decir, de Estados debilitados, escuálidos, muy poco democráticos y -quizá menos aun- republicanos.

El mito más negativo -por inmovilizante- nos hace creer que vivimos en Estados con instituciones sólidas, basadas en principios democráticos y republicanos, garantizados en el plano regional por un derecho internacional eficaz, cuando nada de eso es verdad. Nadie compraría otro atuendo si creyese que el que lo viste es de máxima elegancia, cuando en realidad está en harapos que ni siquiera cubren sus partes pudendas.

Si bien no existe un único modelo democrático, el que se generalizó en la región es el de las democracias plurales, en que la ciudadanía canaliza su voluntad a través de partidos políticos. Pues bien, de este modelo institucional democrático, en nuestros Estados sólo quedan restos.

Esto obedece a que los partidos políticos sólo existen formalmente, pues su función canalizadora la ejercen las corporaciones que monopolizan la comunicación en cada país: desde el análisis funcional, cada una de ellas es un partido político y, además, por monopólica, es un partido único. El monopolio de estos partidos únicos funcionales al poder colonial se presenta como derecho a la libertad de expresión, cuando en realidad es su más abierta negación.

En las concentraciones urbanas, el voto de altos porcentajes de ciudadanía se manipula, conforme a los conocidos once principios de Göbbels, llevando al extremo el consabido teorema de Thomas: no importa que algo sea verdad o mentira, lo que importa es que se lo dé por cierto y en ese caso produce efectos reales. Son las profecías autorealizadas. Las fake news circulan a mayor velocidad que la información correcta, incluso 
por las redes -cuya tecnología también es monopólica-, donde se arman ejércitos de trolls y de ingenios que simulan personas.

De este modo se determina la conducta de buena parte de la población, que de buena fe vivencia la realidad creada por los actores disfrazados de comunicadores, algunos tan consustanciados con los personajes de sus libretos que llegan a creer las mentiras que divulgan.

Estos partidos políticos únicos y mediáticos fabrican a los virreyes locales del totalitarismo financiero $\mathrm{y}$, por ende, como todo aparato de propaganda totalitario, no reconocen ningún límite ético ni legal.

Los políticos son rehenes de estos partidos únicos, que les marcan las agendas, sabiendo que entre los que luchan por el poder siempre habrá algunos más inescrupulosos que, sin duda, llevarán ventaja sobre los que ofrezcan alguna resistencia, como también sobre los que sean menos genuflexos por temor o por restos de dignidad y ética, pero que tampoco se animen a denunciar y menos a resistir sus amenazas de linchamiento. Saben muy bien que, en muchos casos, estos últimos también cederán a sus directivas, porque juegan con su ingenuidad, haciéndoles creer que su silencio los cubre de ser blancos de sus disfrazados de comunicadores.

Los políticos más inescrupulosos disputan para convertirse en candidatos a virreyes de los partidos únicos mediáticos, pues saben que cuando éstos los ungen como tales, tienen altísimas probabilidades de trepar a los gobiernos, con una falsa aureola de democracia. A veces, cuando al virrey ha ejercido su poder colonial con demasiada avidez y torpeza, su reelección fracasa, como en la Argentina. En algún otro caso, el virrey traiciona a su propia fuerza política, proclamándose tal una vez en el gobierno.

Esas democracias de partidos mediáticos únicos suelen asumir formas plebiscitarios, puesto que, una vez en el gobierno, los virreyes ejercen plenos poderes en abierta violación a los principios republicanos, a veces mediante plebiscitos explícitos, pero en la mayoría de los casos, de hecho y ante la indiferencia 
pública, sostenida por la desinformación de la misma publicidad del régimen.

La primera preocupación de los virreyes es el reacomodamiento de los poderes judiciales a su gusto, puesto que de ellos depende la impunidad de sus mandantes, socios y amigos, como también la persecución y difamación de sus opositores y obstaculizadores.

Del grado de previo deterioro de la organización judicial depende la facilidad de estas maniobras. Por lo general, las corporaciones judiciales se integran con personas que privilegian su estabilidad laboral, por lo cual, la docilidad se obtiene, en primer lugar, con el ofrecimiento de algunas racionalizaciones o mecanismos de huida que permitan su pax burocrática.

Al igual que en cualquier estamento profesional, en el judicial hay algunos inescrupulosos y también unos pocos delincuentes, de los cuales se sirven los virreyes y que, por regla, se ofrecen a servirlos, sea en procura de rápida promoción jerárquica, por afán mediático, por aspiración al estrellato político o por corrupción.

Nuestros virreyes cumplen el mandato metrópolitano eliminando a quien les molesta. Este colonialismo no los mata, como a Sucre, Moreno, Monteagudo, Dorrego o al mismo Bolívar, si antes no lo hubiese hecho la tuberculosis, ni los manda al exilio, como a San Martín. Elimina a los líderes políticos groseramente, con golpes de Estado abiertos, como en Bolivia, pero otras veces orquesta golpes blandos, que prostituyen a la política, pues explotan los bajos instintos de lo peor de ella.

La eliminación de líderes populares por decapitación pública se completa con campañas de los partidos mediáticos de los virreyes, en combinación con un pequeño grupo de jueces patológicos, en bandas de las que forman parte activa agentes de servicios secretos, delincuentes que cobran su arrepentimiento, testigos falsos, fiscales extorsionadores, policías corruptos, etc.

Para estos discípulos de Freisler y Vichinsky, todo es válido: misteriosos escritos detallados; increíbles memoriosos; insólita 
velocidad procesal; invocación aberrante de la doctrina jurídica; clonación de procesos; pluralización de bandas; gobiernos considerados asociaciones ilícitas y, por supuesto, violación de normas procesales básicas. De no ser suficiente, se amenaza y persigue a algún juez que moleste, porque así lo exige la lucha contra el flagelo de la corrupción, convertida en el nuevo Satán de este tiempo, con el que pactarían las nuevas brujas, que son los políticos populares.

Mientras estos shows de manos limpias son dramatizados por los partidos políticos mediáticos, los virreyes -y sus socios, parientes y amigos- endeudan a nuestros países, comprometiendo sus PBI por décadas, al tiempo que se benefician con negociados encubiertos por sus cómplices judiciales.

A esto se le llama lawfare o guerra legal, cuando en realidad es una guerra ilegal en todo sentido. Tal es la dimensión que ha cobrado este recurso, que es materia de análisis cada día más intenso en las academias jurídicas.

El último virrey argentino acabó también con el Legislativo, valido del poder de ahogar económicamente a los gobiernos provinciales. Nuestro federalismo se fue por la cloaca al igual que la separación de poderes republicana, con el ejercicio de plenos poderes, no otorgados por nadie. Otros son más burdos, embargando bienes de los legisladores de la oposición o amenazando a sus familias.

¿Qué queda de le república, de la democracia y hasta del Estado mismo? Sólo el resquicio de sentido de realidad de una parte de la ciudadanía, porque -por fortuna- no existe un sistema perfecto de matricería humana.

\section{IV. ¿Qué hacemos ahora?}

Ante la evidencia de que los Estados -como repúblicas y democracias debilitadas- no podrán superar sanamente la conflictividad inevitable de la postpandemia, nos urge pensar en un nuevo modelo de Estado que, tarde o temprano surgirá, así como lo hizo el New Deal de Roosevelt, o sea, en un modelo 
neoprovidente, con mínima equidad desconcentradora de riqueza, capaz de reconstruir las democracias y las repúblicas, asimilando las experiencias de nuestras accidentadas historias.

En nuestro constitucionalismo no habrá de faltar creatividad para pensar modelos de Estados fraternos que, junto a la libertad y la igualdad, no olviden la fraternidad. Nuestros movimientos populares de todos los tiempos nos dejaron pistas redistributivas, que se deben profundizar.

De nuestra región surgió el constitucionalismo social con la Constitución Mexicana de 1917; también apareció el ambiental, con las Constituciones de Ecuador y del Estado Plurinacional de Bolivia. Seguramente de aquí habrá de surgir el constitucionalismo socioambiental, configurador de los nuevos Estados neoprovidentes y fraternos.

Las emergencias están dando la razón a los políticos decapitados por los particos políticos mediáticos y, donde falten, otros surgirán, como sucede en toda emergencia. La política y el vacío son incompatibles: ante el reclamo de las ciudadanías, algo emerge. Además, nuestros pueblos siempre han producido caracteres políticos fuertes; esta capacidad no se ha perdido, pese a los aparatos publicitarios de los particos mediáticos únicos.

Esta tarea jurídica creativa se impone, pues no es suficiente con sacudirse la dependencia colonial, sin perfilar nuestros futuros Estados, porque la historia demuestra que esa actitud es un gravísimo error. En efecto: cuando hace doscientos años nos liberamos del colonialismo originario, nuestras oligarquías y sus intelectuales iluminados quisieron imponer -a sangre y fuego- a los pueblos de nuestra región -supuestamente bárbaros e ignorantes-, modelos incompatibles con nuestras realidades (la llamada civilización genocida). Sobre esas pretensiones se montó el neocolonialismo, lo que costó muchas más vidas y dolor que la propia lucha por la independencia. Ni siquiera podemos descartar que buena parte de las fallas de nuestro presente sea consecuencia de ese error originario. 
Pensar desde ahora el modelo de Estado al que queremos llegar no es un sueño vano, un entretenimiento de ociosos ni implica caer en la utopía, sino que es una tarea indispensable: se trata, nada menos, que de montar la brújula, otear el norte, clarificar el objetivo.

Debemos pensar con urgencia qué Estado queremos, qué institucionalización es necesaria para reconstruir la democracia y la república, cómo recuperar el Estado para la política, cómo volver a una democracia plural con partidos políticos no mediáticos ni por acciones, cómo establecer cierto orden institucional que impida que cualquier virrey circunstancial ejerza la suma del poder público y, sobre todo, cómo revertir el modelo de sociedad con $30 \%$ de incluidos y el resto excluido, que nos intentó imponer el colonialismo del totalitarismo financiero.

No somos ingenuos, sabemos que, en la postpandemia, especialmente frente a las clases medias que caerán en la pobreza, los virreyes y los otros agentes, pretenderán atribuir todos los males a los políticos que no respondan al partido mediático único, usarán sus campañas sucias, sus fake news, las dramatizaciones de sus actores y actrices disfrazados de comunicadores y periodistas; no ahorrarán recurso alguno, recurrirán y pondrán en práctica sus impudicias coprófilas más abyectas e inhumanas. ¿Podrán con todo eso impedir la vuelta de los líderes populares decapitados por los partidos mediáticos únicos o el surgimiento de nuevos lideratos en nuestros países?

Frente a las respuestas demasiado pesimistas, nuestras historias nos enseñan que, con marchas y contramarchas, nuestros pueblos siempre toman conciencia y triunfan. Prueba de esto es que, de no ser por nuestros movimientos populares, quizá no hubiésemos podido escribir estas líneas ni el lector leerlas, porque es muy probable que hubiésemos sido analfabetos, que hubiésemos muerto en la infancia, que tuviésemos menos neuronas por carencia de proteínas en los primeros años o fuésemos desaparecidos por alguna dictadura genocida. 
El cardenismo mexicano, el aprismo peruano, el velasquismo ecuatoriano, el varguismo brasileño, el yrigoyenismo y el peronismo argentinos, etc., tuvieron muchos defectos, incluso algún autoritarismo, pero en el balance final, todos esos defectos empalidecen frente a los genocidios de los virreyes que en todos los tiempos los combatieron y, en definitiva, a ellos debemos la ampliación de la ciudadanía real en nuestra región. Nuestros pueblos no perdieron ni perderán esta vocación, pese a los esfuerzos tecnológicos de los actuales partidos únicos mediáticos.

\section{V. ¿Quiénes deben pensarlo?}

Cuando en Querétaro, los diputados constituyentes campesinos y obreros propusieron las normas que dieron origen al constitucionalismo social, los objetaron los licenciados formados en las universidades del porfiriato. Por suerte triunfaron los primeros. Es llegada la hora de no repetir el error de los últimos.

Es tarea de la academia jurídica superar su vocación elitista y su falsa asepsia política, dejando de lado las pretensiones de quienes se encargan de ofrecer discursos facilitadores de mecanismos de huida hacia la pax burocrática judicial, postulando un derecho apolítico, neutro, incontaminado, que niegue la esencia cultural, histórica y política del derecho, en definitiva, funcional a los virreyes de turno.

El propio estructurador del método dogmático jurídico -Rudolf von Jhering-, a poco dio un giro hacia la realidad social y, con las inevitables limitaciones de su época y lugar, redefinió al derecho como lucha.

La hora llama a los juristas de nuestra región, en homenaje a demanda de recuperación de la soberanía de nuestros pueblos por vía democrática y en el marco republicano y no violento, a sumergirse y empaparse de las necesidades y reclamos de los más victimizados por el tardocolonialismo financiero, para discutir la mejor manera de concretarlos en la forma jurídica de nuevos proyectos de Estado. 
Esto no significa un desvío reaccionario hacia un romanticismo jurídico que pretenda la captación de sentimientos, sino que lo que se exige es comprensión de necesidades, que es algo muy diferente, porque parte del respeto al otro, a la persona en concreto que reclama ciudadanía real.

Debemos ser conscientes de que esos proyectos no deben ser elaboraciones de gabinete, sino que su contenido habrá de surgir de los reclamos fundados en las necesidades de las capas más sufrientes de nuestras ciudadanías, que son o pasan a ser mayoría, debiendo ser las principales proveedoras de su contenido. A los juristas corresponde únicamente la tarea de elaborar el envase jurídico más eficaz posible. La demarcación de contenido y envase es fundamental, para que nadie incurra en el error de los licenciados de Querétaro, pretendiendo elitistamente dar el contenido de lo que sólo debe ser la necesaria envoltura normativa del reclamo de los pueblos.

Teniendo en cuenta que la postpandemia exigirá un esfuerzo conjunto de los pueblos de nuestra región, corresponderá a los internacionalistas meditar el reforzamiento de los organismos regionales, la resurrección de otros y la creación de nuevos, así como reencausar a los que se han vuelto funcionales al totalitarismo financiero y, sobre todo, perfeccionar el reaseguro del sistema regional de Derechos Humanos, para darle la eficacia y prontitud de que ahora carece.

Nuestros jueces no nacen de incubadoras, sino que los formamos en las universidades, revisemos con cuidado y a la luz de las necesidades de nuestros pueblos, lo que estamos teorizando y enseñando: es la hora de una extrema responsabilidad académica.

\section{VI. ¿En qué punto estamos?}

El grado de esfuerzo que demande llevar al plano de la realidad los nuevos Estados neoprovidentes y fraternos que es indispensable que pensemos, dependerá en gran medida de la dinámica del poder planetario en la postpandemia. 
Es claro que la actual paralización de la economía global es el ocaso del totalitarismo financiero, pero no sabemos si es el comienzo o el fin de esta caída. Si se tratase del comienzo, restaría una lucha por delante; si se tratase del fin, sería un amanecer y en breve deberíamos lanzarnos a la construcción del Estado postpandemia.

¿El mundo -la humanidad- se halla en una situación que guarda cierta semejanza a 1939, a 1945 o a los años intermedios? No faltan quienes creen que el ocaso ni siquiera comienza y que, por el contrario, se reforzará en la postpandemia; imaginan diferentes distopías.

Creemos que el camino de distopía choca con un grave inconveniente, puesto que, como conduce a una hecatombe total y esa perspectiva -a pesar del negacionismo- se va haciendo demasiado inocultable, genera creciente pánico generalizado.

El segundo inconveniente del camino distópico, es que con urgencia debería eliminar o deslegitimar a todos los organismos internacionales. Si bien en su momento éstos fueron creados por los poderosos, con la desaparición del mundo bipolar adquirieron dinámica propia y generaron su personal técnico, o sea que, a pesar de su dependencia financiera, se autonomizaron y obstaculizan cada vez más al totalitarismo financiero.

Este distanciamiento estalla hoy en confrontación, pues es inédito el desafío y la difamación contra la OMS. Todo indica que a la OMS seguirán todos los organismos universales y regionales, no sólo de Derechos Humanos, sino aun los más técnicos y especializados. Cualquier perspectiva distópica no podría avanzar sin acabar con los organismos internacionales, con el discurso de Derechos Humanos y también con todo el derecho internacional, incluyendo a la propia Cruz Roja.

Si bien estos organismos están lejos de gobernar el mundo, su empoderamiento tampoco puede subestimarse, en especial por el desprestigio que acarrea a quienes confrontan con ellos, sin perjuicio del que, por otras razones, van cargando ahora esos voceros. 
Asumiendo incluso la posición del comienzo del fin, que sería la más pesimista entre las no distópicas, nos hallaríamos frente al desafío de una lucha por liberarnos de la actual etapa de colonialismo.

Teniendo en cuenta que siempre el derecho es lucha, en cualquier caso, debemos comenzar a meditar qué haremos una vez independientes o, lo que es casi lo mismo, para qué queremos la independencia., pues la caída de otro colonialismo no debe tomarnos desprevenidos, como hace dos siglos largos.

Que nos ilumine Dios, la razón o lo que cada uno crea con total y absoluta libertad de conciencia, porque en esta hora los errores tendrían consecuencias demasiado graves. 